Rev. Latinoam. Psicopat. Fund., São Paulo, 22(2), 376-397, jun. 2019

http://dx.doi.org/10.1590/1415-4714.2019v22n2p376.12

\title{
Traducir: Freud*1
}

\section{Translate: Freud}

\author{
Gianfranco Cattaneo*2 \\ Niklas Bornhauser*3
}

La traducción posee una relevancia crucial tanto para escribir la historia crítica del psicoanálisis como para enfrentar la pregunta por su transmisión. Se inscribe en un campo tensión que se extiende entre el imperativo a traducir y su imposibilidad. El diálogo con el psicoanálisis tiene un rendimiento aún no del todo agotado para una discusión pendiente acerca del estatuto y los límites del traducir. Esta operación, en la medida en que mantiene relaciones diversas con la norma y la exclusión, juega un rol clave a la hora de examinar el límite entre lo normal y lo patológico.

Palabras Clave: Traducción, indecible, lengua, cultura, pulsión

*1 Texto escrito en el marco del Proyecto FONDECYT Regular 1171146 "Lengua, traducción, pensamiento: Hegel - Freud - Hamacher.

*2,3 Universidad Andrés Bello (Santiago, Chile). 


\section{LITERATURA, ARTE, CULTURA}

Porque si soy psicoanalista, soy también un hombre, y, en tanto que hombre, mi experiencia me ha mostrado que la característica principal de mi vida y, estoy seguro, de aquella gente aqui presente — si hay alguien que no esté de acuerdo espero que levantará la mano - es que la vida es una cosa, como se dice en frances, que va a la deriva [à la dérive]. La vida sigue el curso del río, tocando de tiempo en tiempo la rivera, deteniéndose a veces aquí o allá, sin comprender nada - y ese es el principio del análisis, que nadie comprende nada de lo que acontece. La idea de una unidad unificante

de la condición humana tuvo siempre para mi el aspecto de una mentira escandalosa.

Jacques Lacan

\section{Introducción}

\section{El papel de la traducción en la transmisión del psicoanálisis}

Hoy en día, el pensamiento de Freud nos es accesibles a través de las distintas ediciones de sus textos: Gesammelte Werke, Gesammelte Schriften, Studienausgabe, Standard Edition of the Complete Psychological Works of Sigmund Freud, Euvres complètes de Freud, entre otras. En el caso del castellano, de manera abreviada, esto es, pasando por alto las múltiples vueltas de la historia que condujo al establecimiento de cada una de ellas, ${ }^{1}$ se dispone de dos

${ }^{1}$ El lector interesado en el problema de las traducciones y ediciones de Freud al castellano puede remitirse a Wolfson, L. (2008). Ver cómo se traduce a Freud. Revista de historia de la traducción, 2, X-XX; García de la Hoz, A. (1985). Freud en castellano. Revista de la Sociedad Española de Crítica de Libros, 36, 2-9. Para las ediciones de Freud en alemán, véase Grubrich-Simitis, I. (1989). Zur Geschichte der deutschsprachigen Freud-Ausgaben (Teil 1). Psyche, 43(9), 773-802 y Zur Geschichte der deutschsprachigen Freud-Ausgaben (Teil 2). Psyche, 43(10), 889-917. Respecto de las ediciones en francés en general y cómo dichas traducciones habrían afectado el pensamiento psicoanalítico en Francia, consúltese Quinodoz, J.-M. (2010). How translations of Freud's writings have influenced French psychoanalytic thinking. International Journal of Psychoanalysis, 91, 695-716. 
ediciones: las Obras Completas, traducidas por Luis López Ballesteros y de Torres, publicadas en 17 volúmenes entre los años 1922 y 1934 por la editorial madrileña Biblioteca Nueva y luego completadas por cinco volúmenes traducidos por Ludovico Rosenthal; y las homónimas Obras Completas, traducidas por José Luis Etcheverry, publicadas por Amorrortu editores entre 1973 y 1985. Una larga — y, a ratos, bizantina — discusión sobre cuál de las dos versiones sería la mejor, en términos de la más adecuada para la enseñanza y transmisión del psicoanálisis, la más fiel al pensamiento o la intención de Freud, etc. perdura tenazmente. Sin desatender la pertinencia y legitimidad que dicho debate comporta para toda investigación seria acerca de la obra freudiana, en lo que sigue, quisiéramos desarrollar un interrogante que permanece más acá de los términos de la discusión. La lengua alemana, la lengua de Freud - o, mejor dicho: una de las lenguas de Freud, ya que es sabido que Freud hablaba más de una lengua y que Freud se habla, en la actualidad, simultáneamente en más de una lengua - ¿comporta alguna cualidad, acaso alguna formalidad, que determinaría la recepción y transmisión de la conceptualidad freudiana en otras lenguas?

Hay en esto un "hecho de estructura", como sostiene Héctor Yankelevich, que homologa el "bilingüismo del inconsciente" con el "binario lingüístico" constitutivo de la instalación del psicoanálisis (Yankelevich, 2014, p. 127). Es decir que, para el psicoanálisis, son enormes las consecuencias de un hecho, en apariencia, banal: que su práctica pueda ser llevada a cabo en otra lengua que aquella en la que el inconsciente fue descubierto. En lo que concierne a su historia, la principal resistencia hallada por la práctica freudiana, no fueron los ideales gemelos de la cultura americana y anglosajona, que cristalizaron el discurso psicoanalítico de posguerra: el reforzamiento del yo y el analista como modelo y medida de su realidad. Antes que una cuestión de resistencia cultural, de lo que ahí se trató, fue de un problema de lengua. Era el pasaje entre lenguas, "prenda indispensable para su expansión internacional, lo que la condujo a amoldarse a los cimientos de la cultura anglosajona: un lazo social hecho tanto a partir del discurso de la ciencia, triunfante y universal, como de una sociedad formada por comunidades y ética protestante". Esta resistencia del psicoanálisis, en el psicoanálisis, nace "insidiosamente por el movimiento mismo de su avance"; la resistencia nunca fue simplemente exterior al psicoanálisis, sino que provino de lo mismo que permitió su expansión y transmisión (p. 128).

Cuando preguntamos por la "cualidad" del alemán, no hacemos referencia a la necesidad de mantener, o incluso de restaurar, la lengua 


\section{LITERATURA, ARTE, CULTURA}

de origen del psicoanálisis. Aclaremos de entrada que todo proyecto de eventual restitución del "alemán de Freud", asociado o no a alguna aspiración, acaso preservadora, compulsiva o simplemente reaccionaria, de "retorno a los orígenes", de antemano está destinado al fracaso. Como es sabido, la Viena finisecular de Freud era una verdadera Babel, en la que se hablaban simultáneamente, aunque en ambientes o círculos delimitados, francés, húngaro, alto alemán, austríaco (que viene a ser un dialecto del alemán), ruso, entre otros. En el caso de Freud, hay que considerar, además, el yiddish y, según cuenta la leyenda, el castellano - y esto sin contar los innumerables idiolectos: el discurso de la academia, el discurso de las ciencias médicas, el discurso de la burguesía, etc. De esta manera, resulta bastante difícil, por no decir imposible, establecer cuál sería el alemán de origen en el cual están redactados los textos de Freud. Más bien pareciera tratarse de distintas versiones o variantes del alemán, que apuntan a la diversidad de los orígenes y a la imposibilidad de establecer inequívocamente un origen primordial, privilegiado. Por consiguiente, los desplazamientos que las traducciones hacen respecto de algunos de los términos de Freud no podrían achacarse simplemente a un error o a una no comprensión del texto fuente, sino que hacen parte de la traducción como problema, y como problema del psicoanálisis. Entre todos los conceptos freudianos que en principio plantean un desafío para la traducción, algunos de ellos recogidos en el Dictionnaire des intraduisibles (Cassin, 2004), ocupa un lugar destacado la noción de Trieb, cuya concepción, de la mano de Freud, ocurre en franca oposición a la idea de Instinkt, una distinción no siempre conservada en las traducciones a otras lenguas.

Es el alemán "de Freud", su forma de tratar la lengua cuando trataba a sus analizantes, lo que deja una marca indeleble en toda recepción de su obra. Por lo que antes de toda comprensión, es la lectura de esa marca a la que es necesario atenerse para acoger el descubrimiento de Freud. Esto es lo que explica que el apego más riguroso a los conceptos freudianos no sea suficiente para garantizar una práctica psicoanalítica en el sentido de Freud. Y así, el problema de la traducción en tanto que tal, en lo que esta tiene, esencialmente, de equivocación y de inadecuación, de impedimento a la universalidad del concepto, se hace inseparable de todo abordaje, teórico y práctico, del psicoanálisis. Es que el traducir, en palabras de Werner Hamacher, "es una forma lingüística paradojal y una forma paradojal de formas: ella le otorga la palabra a una lengua en otra, sustrayéndole la palabra en su propia lengua; ella es una relación entre las lenguas, pero tal relación que a la lengua desde la cual es traducido le priva la otra, hacia la cual es traducida" (Hamacher, 2010, p. 13) 
El error de la generación freudiana de los años 30-50' fue haberse apartado de estas paradojas y privaciones de la relación entre las lenguas, para considerar que la integridad del concepto lo que podría ampararlos de las derivas del exilio. Su empirismo declarado, no fue otra cosa que una defensa ante el efecto de rechazo que, suponían, podría provenir desde la incomprensión o la equivocación. Es decir, se defendían del acontecimiento del sentido, para poner a salvo, paradójicamente, al mensaje freudiano del gesto con que se anunciaba. De esta manera, la cuestión "de la especificidad de la lengua jamás los rozó, y leyendo a Freud en alemán, las cuestiones inmensas - de la singularidad de su escritura, de la multiplicidad de sujetos sin lazo aparente los unos con los otros, de la homología jamás afirmada como tal entre estratos textuales y estratos del inconsciente, todo eso no ha sido nunca objeto de preocupación, como si el inconsciente pudiera existir por él mismo, como los objetos matemáticos, las leyes físicas o las células, intocado y fuera de toda textualidad" (Yankelevich, 2014, p. 129).

No queriendo saber nada "de cada una de esas junturas delicadas que Freud toma de lo más sutil de la lengua", al moldear de antemano en ellas "las imágenes confusas" de los conceptos en que se precipitaban sus traducciones, se obviaba la letra freudiana como instancia de transmisión (Lacan, 1956/2008a, pp. 348-349). Porque Freud construía, literalmente, los conceptos analíticos al ras de la lengua. Todos los conceptos fundamentales que Freud utiliza los obtiene del vocabulario alemán común y corriente. Nadie antes de Freud había tomado nota que ya en ese nivel, la lengua deja salir a la superficie las impronunciables rupturas que le son inherentes, que toman al hablante por sorpresa al traicionar su intención.

Así es como a través de la pequeña partícula ver-, Freud pudo reconocer tanto de lo que no se admite en la conciencia. Freud observó en los verbos antecedidos por ese prefijo, los intervalos en los cuales se manifiesta lo que no puede hacerlo más que en las "lagunas de la existencia cotidiana". Ver- designa lo que desvía el camino prefijado, pudiendo llegar a invertir el sentido de las palabras hasta su contrario (Goldschmidt, 2017, pp. 72-75). Por lo que Lacan estaba en lo cierto al indicar que las Fehlleistungen, las operaciones defensivas constitutivas de las estructuras clínicas (neurosis, perversión y psicosis), literalmente: rendimientos fallidos, se despliegan casi espontáneamente a partir de dicho prefijo. Y al afirmar que es la ley propia de la cadena significante, como lo hace al comienzo del Seminario sobre "La carta robada", la que rige "los efectos psicoanalíticos determinantes para el sujeto: tales como la forclusión, la represión y la denegación” (Lacan, 1956/2008b, p. 23). Verdrängung, Verleugnung y Verwerfung son formaciones 


\section{LITERATURA, ARTE, CULTURA}

compuestas, junturas significantes que ensamblan tres verbos - drängen: empujar, urgir, apremiar; leugnen: negar, desmentir; werfen: arrojar, proyectar, parir - con el mismo prefijo: ver. Nada hay en estos conceptos que se preste inmediatamente a la intuición. Y aunque en la gramática francesa no exista nada comparable al ver-. en tanto que efecto de una articulación, puede considerarse equivalente al significante que se recoge en el análisis.

La polémica en torno al término Versagung se encamina en esta misma dirección. Según Lacan, este no se encuentra por ningún lado en los escritos de Freud. Afirmación que se demuestra empíricamente falsa, ya que es contradicha por el simple hecho de leer a Freud. Pero que dice la verdad si se sigue lo que, en estricto rigor, sería un concepto en Freud. Es decir, se trata, una vez más, de lo que puede o no ser traducido de Freud. Ahí donde toda una generación de psicoanalistas, limitándose a las perspectivas de la necesidad y su satisfacción, hizo de la "frustración" el motor de un análisis, algo "a llevar a cabo" con sus pacientes con el fin de producir una "regresión" a los conflictos infantiles, Lacan restituye el concepto en lo que este tiene de relación a la palabra, devolviéndole así lo que comporta de insistencia significante. En este sentido, no cabe duda de que Freud nunca habló de frustración. Porque si el interés de Freud, y el del análisis, gira en torno a la cuestión de la sagen, Freud sólo habló de una Versagung "que se inscribe mucho más adecuadamente en la noción de denuncia, como se dice denunciar un tratado o se habla de retractarse de un compromiso. Esto es tan cierto, que incluso se puede poner a veces la Versagung en el polo opuesto, ya que la palabra puede significar a la vez promesa y ruptura de promesa" (Lacan, 1956-57/2005, p. 182).

Por lo tanto, fomentar aquí una elección entre el concepto o la lengua dejaría incólume el problema que buscamos despejar. Porque la misma idea de una elección despejada, implica perpetuar una relación de metalenguaje entre ambos términos. Posición tercera, sin intermediarios, que echa por tierra las prerrogativas del psicoanálisis y de la traducción, al apartar la sobredeterminación involucrada en los desplazamientos de sentido. Antes bien, de lo que se trata, como lo enfatizó Lacan (1964/1987), es de llevar el "concepto de inconsciente" a su límite, lo que significa, para los fines de nuestro trabajo, obligarlo a pagar tributo en la estructura de la lengua, que es de donde todo concepto obtiene su fuerza y determinación. Mientras que el concepto vendría a delimitar y captar [Begriff] lo ya terminado, el inconsciente freudiano es lo "no-realizado". El inconsciente permanece en una especie de "estado larvario", a la espera de una transferencia mediante la cual su impronta podría ser leída. No hay lectura posible de lo inconsciente, si esta lectura no pone en acto un movimiento de transposición, transliteración 
y traducción, con el que podría llegar a trazarse efectivamente su ausencia (Allouch, 1993, pp. 158-159). Otorgarle, entonces, su "forma acabada" al concepto de inconsciente, quiere decir que, al delimitar un espacio de captura de su sentido, algo se ha escabullido ya, irrecuperablemente. Lo que reitera que es la discontinuidad del inconsciente la que posee un carácter inaugural para Freud; su aspecto de tropiezo, de falla o de fisura con que adviene, no logra jamás ser reconducido a una totalidad que le sería anterior. Que no pueda ser llevado hasta la unidad $[U n]$ del concepto, no significa que el inconsciente [Un-bewusste] sea un no concepto [Un-begrff], sino que el concepto de una falta [Unbegriffe] (pp. 31-32).

El sentido insiste, pero hurtándose en el pasaje entre lenguas. Si el fracaso de su captura es la marca de su existencia, la lengua que acoge la transferencia de una formación del inconsciente, debe romper con su propia mismidad, para abrirse no a algo como tal, sino que, a una latencia, puntual y evanescente. Así, mientras se considere eximido del pago que exige acoger la apertura del inconsciente, la rutina del psicoanalista, sostenida en el espejo de su comprensión, correrá el riesgo de transformase en un desconocimiento de la dimensión política que involucra rechazar, de principio, lo imposible de restituir a todo acto de palabra. Una "patología" anterior y más antigua que cualquier enfermedad posible de tratar con un saber referencial le marca el paso al psicoanálisis, desde que sus significantes dejan de ser interpretativos y la interpretación se convierte en explicación pedagógica del funcionamiento psíquico. Será la traducción, considerando al psicoanálisis como una de sus fuentes de reflexión, la que está en condiciones de recordarle esto.

\section{La traducción, entre lo imposible y lo irrenunciable}

En su Éloge de la traduction, Barbara Cassin constata cómo todo pensamiento que pretenda tomar a su cargo la pregunta por la humanidad del hombre, no sólo debe enfrentarse con la exigencia, ya consabida, de que la razón, como condición trascendental, no puede abordarse sin referencia al lenguaje, debido a que la razón, esencialmente, es discurso, sino que, además, todo intento de levantar la hipoteca que encadena razón y lenguaje en la definición del hombre, debe verse en la obligación de relativizar consecuentemente dicha condición, en la pluralidad de un "pensar en lenguas" (Cassin, 2016, p. 31). La "diversidad", Verschiedenheit, con la que Humboldt, en la introducción a su traducción del Agamenón de Esquilo, distinguía esa "única manera en que las lenguas se manifiestan en la realidad", 


\section{LITERATURA, ARTE, CULTURA}

funciona para Cassin como una suerte de paradigma o dispositivo. En él, se enmarca su constatación empírica - de que nunca es con la unidad del lenguaje con lo que un sujeto del discurso tiene que vérselas en la realidad de su enunciación - a la vez que le permite rescatar un término clave para afirmar que la traducción es una experiencia cuyo valor, por encima de las consideraciones técnicas y poéticas, es el de desplazar un régimen ontológico hacia un régimen de la performance (Cassin, 2016, p. 48; 178; 194). Dejamos planteada, en este punto, la pregunta si el régimen en cuestión efectivamente ha de ser uno de la performance, pensado en la senda de John L. Austin y Jan Assmann, entre otros, o acaso de la afformance o adformance en el sentido que Hamacher le otorga al término en sus lecturas de Benjamin y de Man $(1989,1991,1998)$. Debido a que ninguna enunciación real podría ser interpretada fuera de la lengua en que se efectúa, ni permanecer ajena a las demás lenguas que la enmarcan y significan, la diversidad humboldtiana pone radicalmente en cuestión el supuesto de una unidad originaria del sentido como principio organizador del intercambio entre las lenguas. Es decir, que la síntesis de la experiencia de sí y del mundo esté mediada y determinada por el lenguaje, no significa que la traducción extienda el campo de la comunicación, al permitirle a un sujeto hablante la posesión y el uso de más de un código lingüístico.

El lenguaje no es, como se podría suponer, un medio simplemente para decir lo que es, en tanto que es. Al traer al frente el problema de la pluralidad de lenguas, la traducción demuestra que la multiplicidad lingüística no se deja reducir en una superposición de variantes para un mismo sentido, ni a una equivalencia general de los significados en ellas producidos. El corolario ineludible de la labor que Humboldt emprende con el Agamenón, tal como él mismo advierte, es que el poema de Esquilo, debido a su misma naturaleza, es intraducible. Sin embargo, su traducción, como afirma Humboldt a renglón seguido, es una labor ineludible. Es que, como dice Alexander García Düttmann: "La traducción comienza ahí donde la posibilidad del aprender una lengua toca su frontera. Es por eso que ella siempre es traducción de lo intraducible: lo que uno, lo que se traduce cada vez, es la lengua misma, no empero un sentido, que la lengua celosamente almacena y sólo revela a los iniciados" (2001, p. 137). Ahí entonces la paradoja del término que organiza el dispositivo de traducción. La diversidad de las lenguas, como punto de partida, conlleva la imposibilidad de traducción. Porque el poema no sólo es intraducible al alemán. Humboldt no se está refiriendo a una falencia local, a lo que no se puede o no se alcanza a traducir. Lo intraducible del poema afecta a todas las lenguas, porque es lo que habilita la relación y el pasaje entre las 
lenguas. El poema es intraducible porque permanece para siempre abierto a su retraducción (Cassin, 2016, pp. 182-184).

En esta tensión que propone Humboldt entre lo imposible y lo irrenunciable, Andrés Claro (Claro, 2012), ubica la paradoja inicial de la tarea del traductor. Las concepciones de Humboldt acerca de las lenguas constituyen el mayor argumento para declarar la traducción como una pretensión imposible. A partir de ellas, se podrían enumerar todos los escollos que impedirían llevar la tarea adelante con éxito. Y, sin embargo, Humboldt traduce. Porque la experiencia de la traducción, como "utopía irrenunciable", sobrevivirá a todas las teorías de su imposibilidad, siempre que la tensión de la paradoja sea desarrollada y desarticulada. Sólo al incorporar ese imposible, la exigencia permanecerá intacta en su deseo y la tarea alejada de la verdadera amenaza, que es la "traducción absoluta" como "delación o entrega del sentido del otro" (pp. 177-180).

La traducción absoluta, degrada la exigencia de la ley que ordena su experiencia, en un contrato semántico, que pretende regular la posesión y el traspaso del sentido de una lengua a otra, con el fin de poner a salvo al sentido de las distorsiones de forma y el estilo. Este privilegio de la conservación del sentido decanta, a su vez, en una suerte de "círculo vicioso". Porque si la traducción responde a la exigencia mínima del traslado del sentido, "el sentido mismo es definido como lo que permanece invariable o equivalente en la traducción" (ref). El sentido original, identificado con las ideas o pensamientos, debe ser transferido o transportado, idéntico a sí mismo, desde un lugar propio hasta uno ajeno. Si esta concepción corriente y dominante de la traducción, omite preguntarse por la contradicción en que se afirman sus pretensiones, es por su apego a la etimología. En las lenguas europeas, la promesa está ya inscrita en la palabra "traductor". El traductor "es un trans-ductor, el que hace pasar a la otra orilla, de una legua a otra". Y como tal, siempre queda con una "deuda semántica". Al no poder cumplir con lo que se comprometió, traiciona su misma tarea (pp. 50-53). Andrés Claro, en 'El contrato de transporte y el naufragio del sentido: las concepciones lingüístico-trascendentales de W. von Humboldt', primero recuerda la siguiente referencia a Jakob Grimm: "La tarea de la traducción se puede explicar con la misma palabra que la expresa, si bien cambiando el acento: uebersetzen es úebersetzen ['traducir' es 'conducir a la otra orilla'], traducere navem. Quien está dispuesto a navegar y pretende tripular una nave y, con velas desplegadas, conducirla a la otra orilla, debe efectivamente desembarcar en un lugar donde hay otro suelo y sopla otro aire" (Grimm en Claro, Grifo 21, p. 20); para luego interrogar los supuestos fundamentales 


\section{LITERATURA, ARTE, CULTURA}

que subyacen a esta metáfora fluvial, en rigor: metáfora de una metáfora, presupuestos relacionados con la cognoscibilidad del sentido, su estabilidad e invarianza, su capacidad de amoldarse a nuevos recipientes, la posibilidad que éste sea trasvasijado, puesto en circulación, el hecho que el traducir corresponda al vehículo, transporte, pasaje o comercio de este sentido y, por último, que haya un mar, un río, un agua que atravesar, es decir, un medio de paso, idealmente continuo, a través del cual la integridad semántica, sin sufrir alteraciones en cuanto a su sentido, puede ser conducida de una orilla a otra, una lengua a otra. Su acucioso examen de los presupuestos de la concepción de la traducción como un simple transporte de sentido, acaso cognoscible y estable, acepción que la tradición occidental del pensar insiste en encomendarle al traductor, no implica que el traductor literario estaría condenado a la frustración y melancolía ante la imposibilidad, sino que más bien significa que la tarea literaria que se ha realizado históricamente es algo muy distinto: "Pues si la traducción poética comienza reconociendo ciertos límites infranqueables — desde ya, la renuncia a priori a la posesión y el traspaso del sentido pleno, único de lo que se ha dado cuenta aquí —, se determina positivamente ya como una acogida a las formas de significar de la obra extranjera, acogida cuyos efectos estilísticos y semánticos en la lengua propia son a menudo inanticipables. Y si esta acogida se diacroniza como un despliegue de la significación pendiente en las obras del pasado al ser reinscritas en un nuevo tiempo, el doble movimiento de hospitalidad poética que se discierne - en el espacio y en el tiempo — va forjando un lenguaje del parentesco ya no como la identidad y universalidad de una gramática de la razón, sino como el desplazamiento y contagio activo entre las formas de decir de las diversas lenguas particulares" (Claro, 2012, p. 23).

La intuición de Humboldt, ya anticipada en Hamann, de la inseparabilidad de pensamiento y lenguaje, es un argumento implacable contra la mera posibilidad de transportar el sentido. Cabe mencionar, en este punto, que las reflexiones aludidas, todas ellas redactadas en alemán, no distinguen entre lengua o idioma [Sprache] y lenguaje [Sprache]. Dicha indistinción, más que una merma, un déficit respecto de otras lenguas, que sí establecen esta diferencia, ha de ser considerado el recurso potencial de la lengua alemana para pensar justamente la relación entre lengua $\mathrm{y}$ pensamiento. El lenguaje, "como principio activo que impone su síntesis para la captación de los fenómenos", es una forma anterior, la condición de posibilidad del polo subjetivo y el objetivo (p. 62). El lenguaje es el ámbito donde habita el hombre, por lo que el lenguaje, conjuntamente, condiciona su pensamiento y le entrega un "mundo" de objetos. Si tanto el pensamiento 
como la experiencia objetiva del mundo están indisolublemente ligados a la forma lingüística, la traducción no podría ponerse por fuera de ese lazo (p. 64). Al aceptar que el contenido y la forma del lenguaje están indisolublemente ligados, "el contrato semántico del traductor sólo podría cumplirse a cabalidad a condición de que las formas de las lenguas fuesen universales, de que existan al menos formas profundas y compartidas tras la diversidad de las lenguas históricas particulares" (p. 65). Pero ese no es el caso. Humboldt desautoriza la idea del mundo como objetividad y la del universalismo de la experiencia, sustentada en una gramática de la razón, para enfatizar el "carácter" de cada lengua, mediante el cual, las lenguas organizan la significación, representan los objetos e interactúan con otras lenguas. Si cada lengua posee su carácter, tal como Humboldt desarrolla en su escrito Über den Nationalcharakter der Sprachen, este imprime, en los que hablantes que la habitan, una visión de mundo inconmensurable con las demás. Por lo tanto, de las concepciones de Humboldt no sólo se concluye que no podría existir un transporte de sentido íntegro entre una orilla propia y otra ajena, sino que "no habría ni siquiera un medio homogéneo para llevar a cabo la navegación o el comercio semántico". La discontinuidad entre las lenguas se vuelve radical, "no se unirían ni diacrónicamente, apelando a raíces primitivas que determinen la significación estable de los términos, ni sincrónicamente, a través de la universalidad de la representación" (pp. 73-74). Entre las orillas de las lenguas, para Humboldt y sus continuadores, hay un corte y un abismo. Así, por ejemplo, la concepción saussureana del signo lingüístico, en su crítica a la comprensión del lenguaje como nomenclatura, también se inscribiría en esta puesta en cuestión de toda posibilidad del transporte semántico entre lenguas. La manera en que lo "arbitrario" enlaza el significante con el significado en el signo lingüístico, impide que pueda separarse, aun si momentáneamente, el significado de su significante en el signo de una lengua, para ir a verificar si este corresponde

${ }^{2}$ Conviene recordar que dicha arbitrariedad, según Saussure, concierna a la naturaleza del signo lingüístico en cuanto el nexo que une el significante al significado es arbitrario, entendiendo por arbitrario que "es inmotivado, es decir, arbitrario en relación con el significado, con el cual no tiene nexo ninguno natural en la realidad" (Saussure en Benveniste, 2007, p. 49). Benveniste concluye, a partir de lo anterior, que, a partir del mentado principio de arbitrariedad, puede hablarse simultáneamente de la inmutabilidad y mutabilidad del signo: "inmutabilidad porque, siendo arbitrario, no puede ser puesto en tela de juicio en nombre de una norma razonable; mutabilidad porque, siendo arbitrario, siempre es posible de alteración" (p. 53). 


\section{LITERATURA, ARTE, CULTURA}

al significado de otra lengua, también este separado de su significante (Claro, 2012, p. 76; Le Gaufey, 2006, pp. 320-321).

La traducción no solamente traiciona sistemáticamente el contrato de la representación o restitución de un supuesto sentido original, al reconocer los límites infranqueables entre las lenguas. Como tarea, tendría además la obligación de transformarse, mientras resista una vez más la tensión de la paradoja, en la experiencia de la imposible reducción de lo extranjero, como tal, a lo propio. La labor del traductor perfila "su rendimiento erótico y ético", en el momento en que deja caer su pretensión de representar el sentido, para responder a la enseñanza básica de la dispersión babélica: "la experiencia de lo inapropiable como experiencia de la reserva del otro" (p. 172). En la no renuncia ante la exigencia de salir al encuentro de la "trascendencia inapropiable" de lo extranjero, con la que se reconoce su desmesura y opacidad, anterior a un sentido estable con el que podría aplacarse o penetrarse, se encuentra la posibilidad de poner en entredicho la manera en que concebimos lo universal (pp. 183-184).

\section{De la "universalidad patológica del logos" a la parte no normada del hombre}

La traducción, en su incesante labor de traducir y retraducir, manteniendo a raya la pretensión de apropiación y restitución del sentido sin pérdidas ni residuos, complica el Universal, es decir, "la relación de la filosofía a la Verdad con mayúscula" (Cassin, 2016, p. 177). Si la diversidad de las lenguas, entendida "como pluralidad diferencial de performances" ( $p$. 54), es el punto de arranque y de arribo de la tarea del traductor, el imposible a (re)traducir en toda traducción, desmonta la copertenencia, recibida como necesaria por toda la tradición ontológica occidental, entre lengua-lenguajerazón. Si resulta imperativo aclarar que las lenguas "son un panteón y no una iglesia" (p. 193), es porque semejante encadenamiento ha tenido un efecto de sacralización de lo intraducible. Mediante su puesta a parte, se hizo posible, con la naturalidad incuestionada de lo que es reconocible por todos y para todos, la jerarquización ontológica de las lenguas, y a partir de ella, la jerarquización ontológica de los hombres que hablan y habitan esas lenguas. Diferenciación entre los hombres, por tanto, a partir de la capacidad de sus lenguas de asentarse en el ser y decir el ser; superioridad e inferioridad de las capacidades de los hablantes para acceder a la historia y a las condiciones 
universales de la igualdad. Sin embargo, la pregunta por el universalismo no puede ser abandonada sin más. Su aporía debe ser reconocida y reiterada en lo que le es fundamental: el universal "no es verdaderamente un concepto, o una idea, más bien es el correlato de una enunciación que produce o no, según las condiciones, un efecto de universalidad" (Balibar, 2016, p. 173). Toda pretensión universalista de decir el Bien, al identificar lenguaje y pensamiento, discurso y razón, bajo la forma de una lengua singular, que se dice y piensa como universal, desconoce que el universal es el universal de alguien. Por esta razón es que hablar verdaderamente es siempre "hablar como yo" y ser verdaderamente un hombre "es ser un hombre como yo".

Esta "universalidad patológica del logos", como la llama Barbara Cassin, se afianza en una retórica y en una lógica que entraman la producción del universal. La humanidad universal no es una universalidad total. Sólo se ocupa de una parte del universo que construye, que es a lo que llama "todos". Al modo de una sinécdoque, se deduce la totalidad teniendo en consideración sólo la parte. Este paso del sentido, que involucra fijar y representar en el hombre el "tipo" de la humanidad como tal, con la finalidad de afianzarla posteriormente en la comunicación de un individuo a otro o de una cultura a otra, permanece adherido a un resto. Al mismo tiempo propio al gesto de paso y ajeno a sus pretensiones, ese resto es el que explica por qué el "bárbaro" tuvo la función de complementar, como objeto de recepción y apropiación, el discurso del humanismo grecoromano. Entre el logos - como lengua singular poseedora de la razón - y aquel residuo que la razón introduce consigo al desplegarse como discurso, se instaura, desde el inicio, una tensión sin mediación. Una conflictividad interna entre lo propio y lo ajeno socava el fundamento de cualquier ideal que se pretenda universalmente válido para la especie humana. Ante la incapacidad del ideal de establecer un lazo deductivo con el extranjero a partir de algo que le sería ontológicamente propio, la salvaguarda de la univocidad del sentido como vía de acceso a la verdad, se convierte en un intento de administrar su presencia. Se lo excluye internamente en la representación de sus diferencias, imponiéndole la lógica del todo o nada: todo hombre está dotado de logos, si y solo si, es un hombre (Cassin, 2016, p. 33). Todos los hombres pueden participar en el universal, mientras permanezcan atados a un grupo histórico o a una comunidad determinada de valores, fuera de los cuales no existen como individuos ni como hombres. Todos los hombres valen como individuos singulares, mientras reconozcan, en la imposibilidad de comunicarse, que la separación es la condición de la igualdad trascendental (Balibar, 2016, p. 164). Bárbaro es el "bla, bla, bla" de la sinécdoque constitutiva del Universal, en lo que esta tiene de digresión e indeterminación para el sentido lógico. Proviene de balbus. De ahí, el 


\section{LITERATURA, ARTE, CULTURA}

balbuceo y Babel. En su imprecisa generalidad, "bárbaro" no parece ser siquiera un nombre. Más bien, parece ser una onomatopeya, con la que se designa el ruido vacilante de la confusión de una lengua que no se comprende. El bárbaro, es aquel del que no se está seguro de si habla, ni tampoco de si es efectivamente un hombre (p. 35). Y, sin embargo, al mantenerlo a raya en los varales del respeto por el prójimo y su diferencia, la desmedida con que el bárbaro originariamente se expresa, ubica lo inasimilable de la proveniencia en los cimientos sobre el que se yergue el ideal.

La exclusión y la atomización es el efecto inmediato de la patología universalista de la lengua única. Que la filosofía haya tenido su parte en esto, se debe al sueño de la ontología de que el concepto resista a la realidad inestable del pasaje entre las lenguas. Dado que el paso del sentido es el paso de la verdad, este paso debe ser asegurado "sea como univocidad, sea como plurivocidad controlada en tanto contenido o capacidad originarios" (Claro, 2012, p. 159). La traducción se presenta así, como una cierta resistencia a la filosofía que se desarrolla bajo los auspicios de la ontología. Por ello, los intraducibles funcionan al modo de síntomas, sintácticos o semánticos, de las diferencias entre las lenguas (Cassin, 2016, p. 60). Porque es el síntoma el que pone en marcha el dispositivo de traducción, al explicitar las dificultades y desarrollar los equívocos, develando el imposible que causa la patología del traspaso absoluto de todas las fronteras. Traducir lo intraducible, como gesto sin clausura, es otra manera de afirmar las diferencias. Libera una posibilidad distinta para el sentido del hombre, al aceptar la incapacidad inicial de la lengua como la marca indeleble de su finitud. La traducción nos pone sobre la pista para dar con aquellas condiciones, adelantadas más arriba, que harían que una enunciación tenga efectos de universalidad.

Las lenguas se hablan y se necesitan al menos dos para hablar una y para saber que es una la que se habla, de la misma manera que se necesitan dos lenguas para traducir. Enfatizando como principio ese "al menos dos", el trabajo de traducción es una nueva vuelta a un problema fundacional para la lingüística moderna: en el origen, en el mundo nunca encontramos sino seres hablantes que se dirigen a otros seres hablante. El uso individual de una lengua por un "sujeto parlante", es caracterizado por la lingüística como una apropiación "reflexiva", cuyo momento decisivo es la enunciación. Las formas pronominales en la lengua, dice Benveniste (2007), son "signos vacíos", siempre disponibles para que un locutor los asuma en cada instancia del discurso. A diferencia de los signos nominales, el yo no remite a ninguna noción constante y objetiva. Sólo remite a sí mismo, como instancia de discurso. Esta es la única realidad del yo y el tú. Yo, significa una instancia 
de discurso presente, que contiene la instancia lingüística yo, mientras que tú significa la instancia que recibe la alocución en la presenta instancia de discurso que contiene la instancia lingüística tú. Las formas pronominales quedan remitidas sólo a la enunciación, cada vez única, que las contienen y hagan reflexivo su propio empleo. La importancia de su función es habilitar la comunicación, "al permitir la conversión del lenguaje en discurso". Identificándose "como persona única que pronuncia yo como cada uno de los locutores se pone sucesivamente como "sujeto". El signo de la enunciación está ligado al ejercicio del lenguaje, donde cada locutor asume el lenguaje entero. Sólo el lenguaje funda en su realidad, que es la del ser, al ego. Como es ego quien dice ego, la subjetividad, en lo que tiene de permanencia y unidad, "no es más que la emergencia en el ser de una propiedad fundamental del lenguaje" (pp. 173-175; 180-181).

Se podría suponer, por tanto, que el ejercicio de traducción, al hacer intervenir "más de una lengua", permitiría reforzar la fugaz apropiación de la enunciación en una lengua, con una apropiación en segundo grado, permitiéndole al sujeto devenir en propietario de múltiples códigos. Pero sucede todo lo contrario, como cabría esperar del hecho de que no es posible disociar del hombre la propiedad del lenguaje. La actividad de la traducción, al asentarse en el vaivén de una lengua en uso, resalta la "combinación paradojal de apropiación y desposesión o desapropiación” (Balibar, 2016, p. 175). Ex-apropiación [ex-appropriation] es la palabra forjada por Derrida para designar esta combinación (Derrida, 1996, p. 46), con la que condensa, como él mismo sostiene, la ley de la traducción y la traducción como ley (p. 25). No tengo más que una lengua, que no es mía. Al no poder ejercer ningún derecho de propiedad sobre la lengua "propia", "mi" lengua, la única que tengo, es inasimilable para mi. Mi lengua es la lengua del otro, anterior a todo sí mismo. Y afirmarse como tal, sí mismo, no elimina dicha condición original que me hace estar allegado en lo que considero mío, sino que repite la división de lo propio en lo propio, con toda la obstinación del "monolingüe". Esta estructura de "alienación sin alienación", de "alienación inalienable" no es sólo el origen de la responsabilidad, "sino que estructura lo propio y la propiedad de la lengua" (p. 48). La única lengua es siempre otra lengua para quienes habitan en ella. Lo "propio" debe ser trabajado y explorado singularmente para abrirse paso. Es lo que sucede a todo hablante, cada vez, singularmente. Las imposibilidades y desigualdades quedan estructuralmente inscritas en la relación entre las lenguas a partir de la instalación de un inapropiable, lo que suministra el mobil y los recursos de la traducción. Lo propio y lo ajeno se convierten así en un límite de paso en la propia lengua, al mismo tiempo que 


\section{LITERATURA, ARTE, CULTURA}

en la lengua extranjera. De esta manera, la práctica de la traducción realiza, a la vez, una "experiencia de las contricciones de la significación y de la sintáxis que no pueden transgredirse a voluntad" y una "experiencia de la libertad, que los lleva a "transformar poéticamente una lengua dada para que pueda recibir las significaciones de otra" (Balibar, 2016, pp. 175-176). El movimiento de acogida y responsabilidad con lo extranjero es lo único que habilita un movimiento de libertad en lo propio (Claro, 2012, p. 170).

La traducción concurre así a una delimitación de la ontología. Al proyectarse como "más de una" — posible, buena, verdadera —, la traducción realiza el desfondamiento de la exigencia de univocidad estricta del sentido del "discurso normal" y levanta la prohibición de la homonimia, que evidencia que el ente está hecho como un sentido. La traducción transgrede regularmente el principio de no contradicción, al confrontar, en un mismo sentido, "dos equivocidades no superponibles" (Cassin, 2016, p. 113).

Para comprender lo anterior, es necesario retrotaerse hasta el momento de la "decisión del sentido", en la que se decreta la normalidad del discurso. Esta decisión transcurre en "una escena primitiva", en la que se decide lo que quiere decir hablar y lo que es un hombre dotado de logos. La escena se desarrolla en el libro Gamma de la Metafisica de Aristotéles (1005b 19-20), en el momento en que es menester la demostración del principio de todos los principios. Pero no podemos confundir el principio con el procedimiento de demostración del principio, ya que el enunciado inaugural "es imposible que lo mismo, simultáneamente, pertenezca y no pertenezca a lo mismo y según lo mismo", es ya una relación indirecta o mediada con el principio. El principio no puede demostrarse, sólo puede solicitarse. Por esta razón, Aristóteles procede por refutación, exigiendo a quienes lo interrogan que, simplemente, digan cualquier cosa, porque todo decir le permitirá desplegar la serie de equivalencias tomadas como evidencias primeras: "hablar es decir algo, decir algo es significar algo, significar algo es significar algo que tiene un sentido y sólo un sentido, el mismo para uno y para otro". Desde que alguien acepta significar, habla al alero de la decisión de Aristóteles, de que el sentido es la primera entidad hallada y hallable, y esta no tolera la contradicción. No que una sustancia funcione como sujeto de predicados contradictorios, sino que "la misma palabra tenga y no tenga el mismo sentido" (Cassin, 2013, pp. 94-95).

Es necesaria la instalación e imposición de un dispositivo, en función de un adversario, para que el sentido cobre sentido, porque la refutación "hace valer que el adversario, al negar el principio, ya lo ha presupuesto" (Cassin, 2013, p. 96). Mientras que Aristóteles le hace oír al animal dotado de logos que mientras acepte significar dentro de lo límites del dispositivo ontológico, 
posee un logos normal-normativizado, el dispositivo de la traducción, apuntalada aquí por el psicoanálisis, le hace oír al hablante que él excede esa norma. Mientras el hombre no renuncie a la sugestión del significante que lo hace descuidar el sentido, su humanidad es incurable en el sentido de Aristotéles. Y es mejor, en tal sentido, dejarse curar que exponerse a ser excluido. El aspecto no normado de su "naturaleza", no implica, por fuerza, tener que definir al hombre a partir de la exclusión. Menos que el animal pero en exceso respecto de una norma que podría representarlo, el advenimiento de otra manera de concebir el logos se vuelve posible.

Consustancial a la manera aristotélica, esta otra concepción del logos, no tiene un único sentido, ni el mismo para todos, aun cuando se lo pronuncie en él y lo que se escuche en él no cese de escucharse como logos (Cassin, 2013, p. 97). Otra dimensión del logos y otra relación entre normalidad y enfermedad es la que adviene cuando se enfatiza, como lo hiciera Lacan siguiendo la letra freudiana, que el significado es un efecto de la combinatoria significante. Porque instalada en la diferencia de los significantes, sus ambigüedades y sus ritmos, su equivocidad entre sonido y sentido, la nostalgia de lo propio no encuentra cura echando mano en el retorno a la identidad de los significados y los referentes, sino haciendo de aquella parte no normada la ley de su porvenir. Ninguna refutación es posible ya cuando las diferencias operan en las lenguas, tal y como ellas se enuncian y experimentan. Para concebir esa parte no normada del hombre como un rasgo esencial de su ser, la traducción requiere dejar caer el cuerpo de las lenguas para exponerlas, cada vez, a la deriva del sentido de los síntomas.

\section{Discusión}

El psicoanálisis debe tanto su nacimiento como su sobrevida a su relación no solamente con la lengua, acaso materna, sino con las lenguas $\mathrm{y}$, en estricto rigor, con todas ellas y con ninguna en particular. Si bien es cierto que el llamado descubrimiento de lo inconsciente, si lo queremos circunscribir a un momento histórico acotado y distinguido, aconteció en el seno de la lengua alemana y gracias, al menos en parte, a las propiedades estructurales de ésta, la apertura de lo inconsciente, que requiere de un la insistencia gesto permanente, reiterado, siempre renovado, obliga a establecer una relación, al mismo tiempo teórica y práctica, con la traducción. No solamente que el texto freudiano demande ser traducido y está a la espera de 


\section{LITERATURA, ARTE, CULTURA}

sus relecturas, emprendidas desde otra orilla, otra gramática, otro vocabulario, sino que el gesto propiamente psicoanalítico, como revela la lectura, principal, aunque no exclusivamente, de Freud, es, en estricto rigor, un gesto traductivo. Para obtener el máximo rendimiento de esta traductivididad inherente, ha resultado provechoso realizar, al mismo tiempo, un gesto de repliegue sobre sí, introspectivo, orientado a preguntarse por los lugares y los efectos del traducir en el discurso psicoanalítico, y otro, centrífugo, extraversivo, que apunta a transgredir las fronteras disciplinares del mismo psicoanálisis, abriéndolo a otras disciplinas, otras prácticas, siempre bajo el signo de la traducción. En especial, la genealogía del forjamiento de los conceptos, el estudio de su tensión con las palabras y los usos de éstas, más que un asunto resuelto, un problema cerrado, actualmente, en el contexto de la revisión de la legitimidad y validez de las fronteras tradicionalmente establecidas, representa un desafío pendiente.

Conceptos como el ombligo del sueño, la extranjería interior y lo ominoso, para nombrar solamente a algunos, representan el potencial reflexivo que porta el psicoanálisis para contribuir a pensar la antinomia entre la intraductibilidad radical, por un lado, y la coerción o el deseo de traducir, por el otro. De esta manera, secunda el establecimeinto de un concepto y de una praxis del decir ajenos a la reivindicación mecánica y estereotipada de las autoridades avaladas por la tradición del pensamiento moderno en Occidente y sus concepciones de saber y de verdad.

\section{Referencias}

Allouch, J. (1993). Letra por letra. Traducir, transcribir, transliterar. (M. Pasternac, N. Pasternac, \& S. Pssternac, Trads.) Buenos Aires, Argentina: Edelp.

Balibar, É. (2016). Des Universels. Essais et conférences. Paris, França: Galilée.

Benveniste, É. (2007). Problemas de lingüistica general (Vol. I; J. Almela, Trad.) México D.F., México: Siglo XXI.

Cassin, B. (2004). Vocabulaire européen des philosophies: Dictionnaire des intraduisibles. París, França: Le Seuil/Le Robert.

Cassin, B. (2013). Jacques el sofista. Lacan, logos y psicoanálisis” (I. Agoff, Trad.) Buenos Aires, Argentina: Manantial.

Cassin, B. (2016). Éloge de la traduction. Compliquer l'universel. Paris, França: Fayard.

Claro, A. (2012). Las vasijas quebradas. Cuatro variaciones sobre "la tarea del traductor". Santiago, Chile: Universidad Diego Portales. 
Derrida, J. (1996). Le monolinguisme de l'autre, ou la prothèse d'origine. Paris, França: Galilée.

García de la Hoz, A. (1985). Freud en castellano. Revista de la Sociedad Española de Crítica de Libros, 36, 2-9.

García Düttmann, A. (2001). Von der Übersetzbarkeit. En C. L. Har Nibbrig, Übersetzen: Walter Benjamin (pp. 131-146). Frankfurt a. M., Alemanha: Suhrkamp.

Goldschmidt, G.-A. (2017). Cuando Freud vio la mar. Freud y la lengua alemana. (N. Bornhauser Neuber, Trad.). Santiago, Chile: Metales Pesados.

Grubrich-Simitis, I. (1989). Zur Geschichte der deutschsprachigen Freud-Ausgaben (Teil 1). Psyche, 43(9), 773-802.

Grubrich-Simitis, I. (1989). Zur Geschichte der deutschsprachigen Freud-Ausgaben (Teil 2). Psyche, 43(10), 889-917.

Hamacher, W. (2010). Kontraduktionen. En G. Mein, Transmission. Übersetzung Übertragung - Vermittlung (pp. 13-33). Viena / Berlín: Turia - Kant.

Lacan, J. (1987). El seminario. Libro 11. Los cuatro conceptos fundamentales del psicoanálisis. (J.-A. Miller, Ed., J. L. Delmont-Mauri, \& J. Sucre, Trads.). Buenos Aires, Argentina: Paidós. (Artículo original publicado en 1964).

Lacan, J. (2005). El seminario. Libro 4. La relación de objeto. (J.-A. Miller, Ed., \& E. Berenguer, Trad.). Buenos Aires, Argentina: Paidós. (Artículo original publicado en 1956-1957).

Lacan, J. (2008a). Situación del psicoanálisis en 1956. En J. Lacan, Escritos 1 (T. Segovia, Trad., p. 431-460). Buenos Aires, Argentina: Siglo XXI. (Artículo original publicado en 1956).

Lacan, J. (2008b). El seminario sobre "La carta robada". En J. Lacan, Escritos 1 (T. Segovia, Trad., pp. 23-72). Buenos Aires, Argentina: Siglo XXI. (Artículo original publicado en 1956).

Lacan, J. (2013). Of Structure as an Inmixing of an Otherness Prerequisite to Any Subject Whatever. Communication faite au Symposition International du John Hopkins Humanities Center à Baltimore. Rescatado de: <http://ecole-lacanienne. net/wp-content/uploads/2016/04/1966-10-21.pdf>.

Le Gaufey, G. (2006). ¿Alucinar? En G. Le Gaufey, El caso inexistente. Una compilación clínica. (R. Pérez, Trad., pp. 311-330). México D.F., México: Epeele.

Quinodoz, J.-M. (2010). How translations of Freud's writings have influenced French psychoanalytic thinking. International Journal of Psychoanalysis, 91, 695-716.

Wolfson, L. (2008). Ver cómo se traduce a Freud. Revista de historia de la traducción, 2, X-XX.

Yankelevich, H. (2014). Lo imposible de traducir. Lapsus Calami. Revista de Psicoanálisis, 4, 127-132. 


\section{LITERATURA, ARTE, CULTURA}

\section{Resumenes}

(Translate: Freud)

Translation is of crucial importance for both writing the critical history of psychoanalysis and discussing the question of its transmission. It is part of a field of tension that ranges from the imperative to be translated to its impossibility. The dialogue with psychoanalysis shows a performance that is not yet exhausted for a pending discussion about the statute and the limits of translating. This operation, insofar as it maintains diverse relationships with the norm and the exclusion, plays a key role when it comes to examining the borderline between the normal and the pathological.

Key words: Translation, unspeakable, language, culture, drive

(Traduire: Freud)

La traduction joue un rôle important à la fois pour écrire l'histoire critique de la psychanalyse et pour traiter la question de sa transmission. Elle fait partie d'un champ de tension qui s'étend entre l'impératif de traduire et son impossibilité. Le dialogue avec la psychanalyse possède une performance qui ne s'est pas encore épuisée en ce qui concerne la discussion en suspens sur le statut et les limites de la traduction. Cette opération, dans la mesure où elle entretient de divers rapports avec la norme et l'exclusion, joue un rôle essentiel quand il s'agit d'examiner la frontière entre le normal et le pathologique.

Mots clés: Traduction, indicible, langue, culture, pulsion

\section{(Traduzir: Freud)}

A tradução tem uma relevância crucial tanto para escrever a história crítica da psicanálise quanto para enfrentar a questão de sua transmissão. Faz parte de um campo de tensão que se estende entre o imperativo a ser traduzido e sua impossibilidade. $O$ diálogo com a psicanálise tem um desempenho ainda não esgotado para uma discussão pendente sobre o estatuto e os limites da tradução. Essa operação, na medida em que mantém relações diversas com a norma e a exclusão, desempenha um papel fundamental quando se trata de examinar a fronteira entre o normal e o patológico.

Palavras-chave: Tradução, indizível, língua, cultura, pulsão

\section{(Freud Übersetzen)}

Die Übersetzung spielt eine entscheidende Rolle sowohl für die kritische Geschichte der Psychoanalyse als auch für die Frage nach ihrer Übertragung. Sie ist Teil eines Spannungsfeldes, das sich zwischen der Notwendigkeit der Übersetzung und deren Unmöglichkeit erstreckt. Der Dialog mit der Psychoanalyse spielt eine noch nicht ausgeschöpfte Rolle in einer anstehenden Diskussion über das Statut und die 
Grenzen des Übersetzens. Da dieser Vorgang verschiedene Beziehungen zu Norm und Ausgrenzung unterhält, spielt er eine Schlüsselrolle, um die Grenzen zwischen Normalität und Pathologie zu erkunden.

Schlüsselwörter: Übersetzung, Unsagbare, Sprache, Kultur, Trieb

Citação/Citation: Cattaneo, G., Bornhauser, N. (2019, junho). Traducir:Freud. Revista Latinoamericana de Psicopatologia Fundamental, 22(2), 376-397. http://dx.doi.org/10.1590/ 1415-4714.2019v22n2p376.12.

Editora/Editor: Profa. Dra. Sonia Leite

Submetido/Submitted: 21.8.2018/ 8.21.2018 Aceito/Accepted: 5.2.2019/2.5.2019

Copyright: @ 2009 Associação Universitária de Pesquisa em Psicopatologia Fundamental/ University Association for Research in Fundamental Psychopathology. Este é um artigo de livre acesso, que permite uso irrestrito, distribuição e reprodução em qualquer meio, desde que o autor e a fonte sejam citados / This is an open-access article, which permits unrestricted use, distribution, and reproduction in any medium, provided the original authors and sources are credited.

Financiamento/Funding: Este trabalho não recebeu financiamento / This work not received funding.

Conflito de interesses/Conflict of interest: Os autores declaram que não há conflito de interesses / The authors declare that there is no conflict of interest.

\section{Gianfranco Cattaneo}

Licenciado en Psicología. Doctor en Filosofía. Psicoanalista. Profesor de la Carrera de Psicología de la Universidad Andrés Bello. Facultad de Educación y Ciencias Sociales.

Miembro de la École lacanienne de psychanalyse.

Fernández Concha 700

Santiago, Chile

https://orcid.org./ 0000-0002-4266-0731

gcattaneo@unab.cl 


\section{LITERATURA, ARTE, CULTURA}

NikLAs Bornhauser

Licenciado en Psicología. Doctor en Filosofía. Psicoanalista. Profesor de la Carrera de Psicología de la Universidad Andrés Bello. Facultad de Educación y Ciencias Sociales.

Fernández Concha 700

Santiago, Chile

https://orcid.org/0000-0001-5655-4668

niklas.bornhauser@gmail.com

This is an open-access article, which permits unrestricted use, distribution, and reproduction in any medium for non-commercial purposes provided the original authors and sources are credited. 